\title{
KOMPONEN - KOMPONEN INCLUSIVE LEADERSHIP PADA SEKTOR PENDIDIKAN DAN ORGANISASI IN SOCIETY 5.0
}

\author{
Choirul Anam $^{1^{*}}$, Tuti Hastuti ${ }^{2}$, Daisy Marthina Rosyanti ${ }^{3}$ \\ ${ }^{1,2}$ Program Studi Manajemen, Universitas Widyagama Malang \\ ${ }^{3}$ Program Studi Manajemen, Universitas Pembangunan Negeri Veteran Jawa Timur Surabaya \\ anam@widyagama.ac.id
}

\begin{abstract}
ABSTRAK
Salah satu bentuk inklusi dalam masyarakat adalah situasi sosial seperti halnya dalam dunia pendidikan. Bagaimana mengetahui batasan-batasan berkaitan dengan menghargai keberagaman suku, agama, ras serta memastikan hak-hak mereka tetap terjaga. Penelitian ini bertujuan untuk menjelaskan kepemimpinan inklusi di era society 5.0 dari konsep dasar sampai pada perkembangan konstruk. Pendekatan yang digunakan adalah studi literature review yang bersumber dari google scholar, sciencedirect, emeraldinsight, buku terbitan internasional maupun buku terbitan lokal. Temuan penelitian menunjukkan bahwa konstruk kepemimpinan inklusi memiliki konsekuensi yang mampu digunakan pada sektor pendidikan dan organisasi, serta sebagai pengembangan sumberdaya manusia yang berfokus pada perilaku kerja. Adapun pengukuran kepemimpinan inklusi yang terdiri dari keterbukaan, ketersediaan, dan aksesbilitas. Penelitian bertema kepemimpinan inklusi akan menjadi tren penelitian pada tahun 2021.
\end{abstract}

Keyword: Kepemimpinan Inklusi.

\begin{abstract}
One form of inclusion in society is social situations such as in the world of education. How to know the boundaries related to respecting ethnic, religious, racial diversity and ensuring their rights are maintained. This research aims to describes inclusive leadership in society 5.0 era from basic concepts to construct developments. The approach used is a literature review study sourced from google scholar, science direct, emeraldinsight, international and local published books. The findings of the study show that the construct of inclusive leadership has consignment that can be used in the education and organizational sectors, as well as human resource development that focused in working behavior. The measurement of inclusive leadership consists of openness, availability and accessibility. Research on the theme of inclusive leadership will become a research trend in 2021.
\end{abstract}

Keyword: Inclusive Leadership. 


\section{PENDAHULUAN}

Kepemimpinan menjadi bagian terpenting dalam kehidupan organisasi baik di sektor privat dan sektor publik. Konsep ini menjadi semakin populer seiring dengan konsistensi temuan antara kepemimpinan dan efektivitas organisasi maupun kepuasan organisasi. Lebih lanjut, teori kepemimpinan pada praktiknya mengungkapkan tendensi mengenai lahirnya kepemimpinan inklusif. Istilah inklusi dalam Dictionary of the America Language (1960), adalah include yang berarti mengelilingi, bagian keseluruhan atau secara keseluruhan termasuk di dalamnya (Ryan, 2006). Salah satu bentuk inklusi dalam masyarakat adalah situasi sosial seperti halnya dalam dunia pendidikan. Bagaimana mengetahui batasan-batasan berkaitan dengan menghargai keberagaman suku, agama, ras serta memastikan hak-hak mereka tetap terjaga (Martin, et al., 2020). Sedangkan kepemimpinan inklusi adalah proses kolektif yang ada pada setiap orang atau yang mewakilinya (Ryan, 2006). Lebih lanjut, Sounders (2005) mengartikan bahwa kepemimpinan inklusi adalah suatu mekanisme untuk memberikan hak berbicara pada suatu sistem dimana akan terjadi proses pengambilan keputusan melalui konsensus.

Dalam teori pembangunan, Wuffli (2016) menyatakan bahwa konsep inklusivitas mengungkapkan kebutuhan untuk secara proaktif memastikan partisipasi masyarakat miskin dan kurang mampu dalam proses pengembangan. Lebih lanjut, dalam teori kepemimpinan yang lebih khusus lagi mengungkap bahwa kepemimpinan inklusif digunakan untuk menekankan lebih banyak keragaman dan pemimpin-pengikut yang memiliki hubungan baik. Artinya, kita membutuhkan sebanyak mungkin pemimpin yang memiliki pemikiran di tingkat makro maupun di tingkat mikro di semua sektor. Kepemimpinan harus menjadi konsep holistik yang dapat diterapkan secara luas, bukan yang ekslusif dengan ambang batas yang berlebihan yang hanya dapat dipenuhi oleh sedikit orang, melainkan harus memimpin secara inklusif (Wuffli (2016).

Terdapat tiga elemen kunci dari kepemimpinan inklusi, yaitu memberikan berbagai pengaruh; proses yang ada dalam setiap pelaksanaan kegiatan, prosedur, pemahaman, dan nilai yang tetap bertahan sepanjang masa; dan dilaksanakan untuk mencapai tujuan tertentu (Ryan, 2006). Sounders (2005) juga menjelaskan perihal rangkaian kepemimpinan (leadership continuum), yang terdiri dari inklusif, emansipatif, demokratik, transformatif, manajerial. Duke (2005) menyatakan bahwa inklusi dapat diterapkan di level manajemen yang berfokus pada pengembangan kapasitas publik untuk berpartisipasi dalam proses kebijaksanaan, konstruk yang dibangun dalam konsepnya terdiri dari komunikasi, informasi, dan keahlian.

Fullan (2001) menguraikan lima komponen penting yang saling berkaitan dengan kepemimpinan inklusi sehingga dapat berjalan secara efektif, yakni tujuan moral, pemahaman terhadap proses perubahan, membangun kemitraan, penciptaan pengetahuan, dan pembinaan hubungan yang logis. Sedangkan Wuffli (2016) menguraikan tentang prinsip dari kepemimpinan inklusi, yaitu dinamis, horizontal, holistik, norma secara eksplisit yang terbentuk dari akselerasi global dan evolusi etika pada tahap gaya tranformasional. Hal ini penting ditelaah mengingat tren yang akan ada di tahun 2021 berkaitan dengan kepemimpinan inklusi (Martin, et al., 2020). Sehingga fokus makalah ini adalah untuk mengetahui komponen-komponen dari kepemimpinan inklusi di berbagai sektor.

\section{TINJAUAN PUSTAKA}

\section{Konsep Kepemimpinan}

Kepemimpinan adalah proses interaksi dalam konteks tertentu untuk dapat mencapai tujuan bersama (Silva, 2016; Northouse, 2016). Kepemimpinan juga mampu mempengaruhi faktor intrapersonal dan budaya (Angraeni, Baharuddin, \& Mattalatta, 2019).

\section{Inclusive Leadership}

Selama 30 tahun kepemimpinan Inklusif terbukti bahwa inklusi memiliki peningkatan dalam studi literature saat ini, seperti pada bidang bidang pekerjaan sosial, psikologi sosial, kepemimpinan, keragaman, manajemen, sumber daya manusia. Selain itu terdapat pada bidang pendidikan, kepemimpinan pendidikan, administrasi sains, dan komunikasi (Thompson \& Matkin, 2019).

Mengacu pada gaya kepemimpinan, inclusive leadership merupakan seorang pemimpin yang menekankan pada kejujuran, adil, dan memperlakukan sikap yang sama dengan bawahannya. Sehingga mampu menciptakan sebuah pemberdayaan, partisipasi, dan keterlibatan karyawan (Rawat et al., 2020). Pemimpin yang memiliki sifat inklusi mampu memberikan ide-ide baru, terbuka, dan dapat saling tukar pikiran dengan karyawan (Carmeli, Reiter-Palmon, \& Ziv, 2010; Kuknor \& Bhattacharya, 2020).

Inclusive leadership berkaitan dengan tren global yang mendukung kebutuhan akan pemimpin yang inklusif. Kedua adalah keragaman. Ketiga, keragaman ide, teknologi digital, hiperkonektivitas (Najmaei \& Sadeghinejad, 2019). Inclusive leadership mampu memberikan keuntungan dalam situasi tertentu guna memelihara kinerja tim maupun psikologis karyawan (Cenkci, Bircan, \& Zimmerman, 2021)

\section{METODE}

Dalam menguraikan proses tahap penelitian, peneliti menggunakan pendekatan kualitatif berdesain literature review dengan paradigma interpretative (Neuman, 2014; Hamzah, 2019; Patel, 2015). Tujuan dari desain literatur review adalah mencari penjelasan tentang peristiwa-peristiwa sosial atau budaya yang didasarkan pada perspektif pengalaman dan pengamatan dengan mengumpulkan bahan-bahan pustaka yang diteliti (Hamzah, 2019). Pustaka yang dikumpulkan bersumber dari sejumlah telaah referensi yang kredibel seperti : springer, sciencedirect, emeraldinsight, sage, . Artikel yang nantinya digunakan sebagai dasar untuk mengidentifikasi komponen-komponen dari inclusive leadership menggunakan software N-Vivo 12. 
HASIL DAN PEMBAHASAN

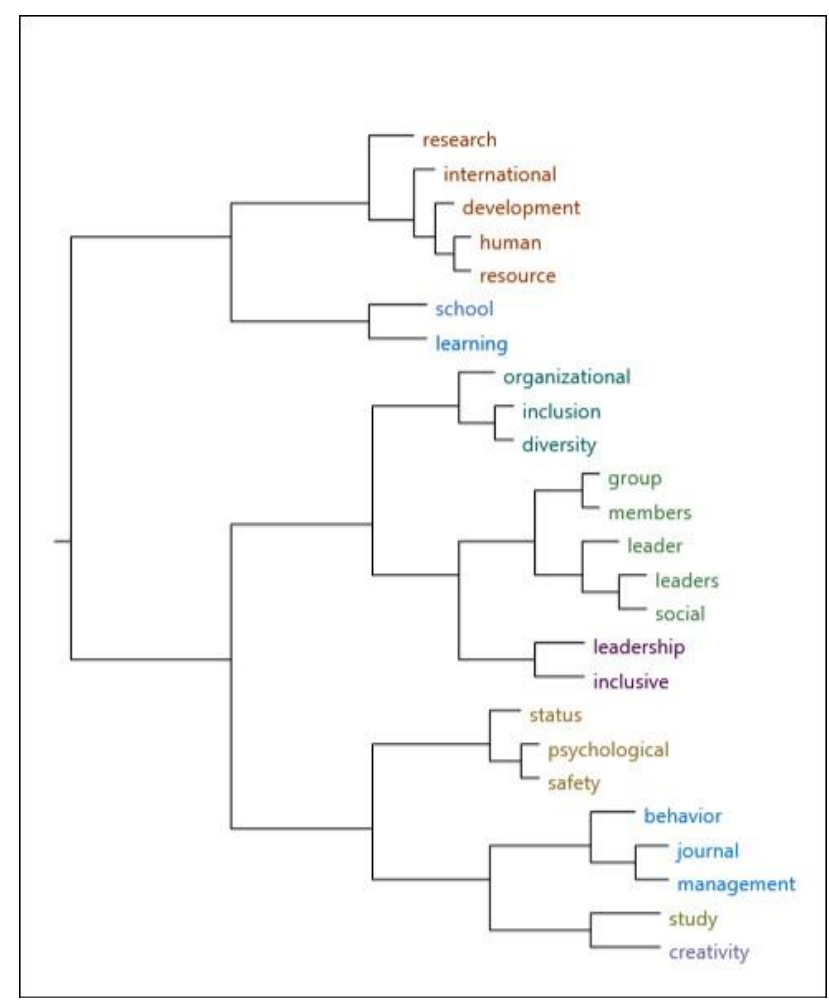

Gambar temuan hasil N-Vivo 12

Dari Gambar diatas diketahui bahwa dari 12 artikel yang digunakan bersumber dari springer, sciencedirect, emeraldinsight, sage dapat diketahui beberapa komponen dari inclusive leadership. Randel et al. (2018) menyatakan bahwa kepemimpinan inklusi memiliki karakteristik yang unik sehingga tercetus pemikiran untuk dapat meneliti topik mengenai kepemimpinan inklusi secara teori maupun kerangka konseptual guna memahami faktor-faktor yang membentuk kepemimpinan inklusi pada kelompok kerja. Randel et al. (2018) menambahkan bahwa kepemimpinan inklusi adalah perilaku pemimpin yang mampu menfasilitasi anggota kelompok guna merasakan rasa memiliki dalam kelompok kerja. Ada beberapa kategori yang diteliti oleh Randel et al. (2018), yaitu perilaku pemimpin, identifikasi kelompok, pemberdayaan psikologis, dan hasil perilaku seperti kreativitas, pekerjaan, kinerja dalam mengejar tujuan kelompok. Hasil temuannya diketahui bahwa ketika organisasi menjadi semakin beragam, para pemimpin perlu memahami bagaimana menjalankan peran mereka dengan cara yang tidak hanya mengambil memanfaatkan keragaman dan memaksimalkan kinerja kelompok kerja, tetapi juga mewujudkan tujuan tersebut melalui perilaku yang inklusi dari semua anggota. Mendorong perilaku kepemimpinan yang inklusif menjanjikan untuk meningkatkan pengalaman pekerjaan dari semua anggota kelompok kerja dan menjadi efektif bagi kelompok dan organisasi.

Tantangan yang terdapat pada kepemimpinan inklusi meliputi Pendidikan inklusif, Praktik Inklusif, Faktor Organisasi, Budaya dan Kepemimpinan, dan Peran Jaringan (Ainscow \& Sandill, 2010). Di samping itu, temuan dari Ainscow \& Sandill (2010) menjelaskan tantangan bagi negara-negara di seluruh dunia dalam mengembangkan sistem pendidikan yang lebih inklusif.
Ainscow \& Sandill (2010) menegaskan pada proses pembelajaran sosial di dalam konteks tertentu. Copland (2003) berpendapat bahwa inkuiri dapat menjadi mesin untuk memungkinkan distribusi kepemimpinan yang dibutuhkan untuk membina partisipasi, dan perekat yang dapat mengikat komunitas sekolah di sekitar tujuan bersama. Semua ini memiliki implikasi besar bagi praktik kepemimpinan di berbagai tingkat dalam sekolah dan sistem pendidikan. Secara khusus, ini membutuhkan upaya untuk mendorong upaya terkoordinasi dan berkelanjutan oleh seluruh kelompok, sehingga gagasan bahwa mengubah hasil untuk semua siswa tidak mungkin tercapai kecuali ada perubahan pada perilaku (Ainscow \& Sandill, 2010).

Kuknor \& Bhattacharya (2020) menemukan bahwa di era saat ini kepemimpinan inklusi mampu berkolaborasi dengan organisasi inklusi. Hal ini membuktikan bahwa sifat kepemimpinan inklusi mampu mendorong praktik inklusi di organisasi, khususnya pada pengembangan sumberdaya manusia (Garavan \& Carbery, 2012; Garavan \& Carbery, 2014). Kepemimpinan, inklusi, dan keragaman adalah salah satu yang berkembang tren dalam penelitian manajemen sumberdaya manusia (Ghosh, Kim, Kim, \& Callahan, 2014). Dalam penelitian Najmaei \& Sadeghinejad, (2019) menemukan karakteristik dari kepemimpinan inklusi, yakni pemimpin inklusif mampu terlibat langsung dalam kelompok, pemimpin inklusi mampu mengundang pendapat semua orang tetapi juga menghargai kontribusi semua orang (Nembhard dan Edmondson, 2006). Untuk mencapai tujuan ini, pemimpin yang inklusif perlu menjadi terbuka, dapat diakses, dan tersedia untuk semua orang (Carmeli et al., 2010).

Deloitte (2012) menyebutkan kepemimpinan inklusi terdapat kesadaran diri, introspektif, mengetahui titik buta, dan memiliki kemampuan untuk mendengarkan dan belajar sebagai karakteristik utama dari seorang pemimpin yang inklusif. Penelitian Deloitte juga menambahkan bahwa pemimpin yang inklusif seharusnya ingin tahu. Keingintahuan dalam hal ini adalah proses yang digunakan oleh para pemimpin memahami perspektif dan kemampuan unik setiap orang, melampaui batas karakteristik atau peran pekerjaan yang menonjol.

Deloitte (2016) merupakan perpanjangan dari Deloitte (2012) yang mengidentifikasi ada enam tanda ciri-ciri pemimpin inklusif: (i) kesadaran karena pemimpin inklusif seharusnya tidak bias terhadap kelompok karyawan tertentu; (ii) keberanian karena berbicara tentang ketidaksempurnaan melibatkan pengambilan risiko pribadi; (iii) komitmen karena bertahan di jalur itu sulit; (iv) kolaborasi karena tim yang berpikir beragam lebih besar dari jumlah bagiannya; (v) kecerdasan budaya karena tidak semua orang melihat dunia melalui bingkai budaya yang sama; dan akhirnya (vi) rasa ingin tahu karena ide dan pengalaman yang berbeda memungkinkan pertumbuhan. Deloitte menyimpulkan bahwa ciri-ciri ini menangkap aspek kognitif dan konatif dari kepemimpinan inklusif karena mereka mencirikan pola pikir inklusif dan perilaku inklusif.

Wuffli (2016) berpendapat bahwa pemimpin inklusif harus (i) dinamis dan berorientasi pada perubahan, (ii) heterarkis (yaitu, membangun jembatan di 
berbagai sektor masyarakat dan lintas budaya), (iii) holistik dan dapat diterapkan secara luas dengan melibatkan sebagai banyak orang dan beragam situasi mungkin, dan (iv) secara eksplisit normatif dalam istilah untuk mendorong para pemimpin untuk merefleksikan dan mengambil posisi yang terkait dengan mereka etika dan kebajikan yang mendasari. Disisi lain, Rawat et al. (2020) kepemimpinan inklusi mampu mementoring dan pemberdayaan atau membantu karyawan yang reaktif secara emosional guna meningkatkan kinerja mereka. Disamping itu, kepemimpinan inklusi mampu diukur dengan keterbukaan, ketersediaan, dan aksesbilitas pada perilaku kerja yang inovatif (Javed, Naqvi, Khan, Arjoon, \& Tayyeb, 2019). Kepemimpinan inklusi mampu menjadi variabel moderasi maupun mediasi (Ye, Wang, \& Li, 2019).

\section{PENUTUP \\ Simpulan}

Berdasarkan hasil pembahasan diatas maka dapat dipahami dan disimpulkan jika kepemimpinan inklusi mampu digunakan pada sektor pendidikan (Ryan, 2006), organisasi (Kuknor \& Bhattacharya, 2020); Rawat et al., 2020) maupun sosial (Ryan, 2006; Martin, et al., 2020), serta sebagai pengembangan sumberdaya manusia (Garavan \& Carbery, 2012 ; Garavan \& Carbery, 2014) pada perilaku kerja yang inovatif (Javed et al., 2019).

\section{DAFTAR PUSTAKA}

Ainscow, M., \& Sandill, A. (2010). The big challenge: Leadership for inclusion. International Encyclopedia of Education, 846-851. https://doi.org/10.1016/B978-0-08-0448947.00453-X

Angraeni, Baharuddin, \& Mattalatta. (2019). Hubungan Faktor Intrapersonal Dan Faktor Kultural Terhadap Kepemimpinan Pengusaha Perempuan Di Sulawesi Selatan. Jurnal Mirai Managemnt, 4(2), 122-136. Retrieved https://journal.stieamkop.ac.id/index.php/mirai

Carmeli, A., Reiter-Palmon, R., \& Ziv, E. (2010). Inclusive leadership and employee involvement in creative tasks in the workplace: The mediating role of psychological safety. Creativity Research Journal, 22(3), 250-260. https://doi.org/10.1080/10400419.2010.504654

Cenkci, A. T., Bircan, T., \& Zimmerman, J. (2021). Inclusive leadership and work engagement: the mediating role of procedural justice. Management Research Review, 44(1), 158-180. https://doi.org/10.1108/MRR-03-2020-0146

Copland, M. A. (2003). Leadership of inquiry: Building and sustaining capacity for school improvement. Educational Evaluation and Policy Analysis, 25(4), 375-395.

https://doi.org/10.3102/01623737025004375

Deloitte. (2012). Inclusive leadership: Will a hug do? Deloitte Australia Point of View. Sydney, Australia.
Deloitte. (2016). The six signature traits of inclusive leadership: Thriving in a diverse new world. Sydney, Australia: Deloitte University Press.

Fullan, M. 2001. The new meaning of educational change (3rd edition). New York: Teachers College Press.

Garavan, T. N., \& Carbery, R. (2012). A review of international HRD: Incorporating a global HRD construct. European Journal of Training and Development, 36(2-3), 129-157. https://doi.org/10.1108/03090591211215579

Garavan, T. N., \& Carbery, R. (2014). Advancing HRD theory: New theoretical perspectives and promoting methodological pluralism. European Journal of Training and Development, 38(4), 262-264. https://doi.org/10.1108/EJTD-03-2014-0028

Ghosh, R., Kim, M., Kim, S., \& Callahan, J. L. (2014). Examining the dominant, Emerging, And waning themes featured in select HRD publications: Is it time to redefine HRD? European Journal of Training and Development, 38(4), 302-322. https://doi.org/10.1108/EJTD-02-2013-0012

Hamzah, A., 2019. Metode Penelitian Kepustakaan: Kajian Filosofi, teoritis dan Aplikasi. Literasi Nusantara Abadi.

Javed, B., Naqvi, S. M. M. R., Khan, A. K., Arjoon, S., \& Tayyeb, H. H. (2019). Impact of inclusive leadership on innovative work behavior: The role of psychological safety. Journal of Management and Organization, 25(1), 117-136. https://doi.org/10.1017/jmo.2017.3

Kuknor, S. C., \& Bhattacharya, S. (2020). Inclusive leadership: new age leadership to foster organizational inclusion. European Journal of Training and Development, (2017). https://doi.org/10.1108/EJTD-07-2019-0132

Martin, Anthonio Dio, Max Sandy, Dian Riupassa, Ahmad Madu, Efina Kartolo, 2020. Tren HR Di Indonesia 2021. HR Excellency. Mini Workshop Series.

Najmaei, A., \& Sadeghinejad, Z. (2019). Inclusive Leadership: A Scientometric Assessment of an Emerging Field. 22, 221-245. https://doi.org/10.1108/s1877636120190000022012

Neuman, W. L., 2014. Social Research Methods: Qualitative and Quantitative Approaches. Seventh Edition. Edinburgh Gate. Pearson Education Limited.

Northouse, P. G., 2016. Leadershop : theory and practice. Seventh Edition. SAGE Publications, Inc.

Patel, S. 2015. The research paradigm-methodology, epistemology and ontology-explained in simple language.

Randel, A. E., Galvin, B. M., Shore, L. M., Ehrhart, K. H., Chung, B. G., Dean, M. A., \& Kedharnath, U. 
(2018). Inclusive leadership: Realizing positive outcomes through belongingness and being valued for uniqueness. Human Resource Management Review, 28(2), 190-203. https://doi.org/10.1016/j.hrmr.2017.07.002

Rawat, P. S., Lyndon, S., Pradhan, M. R., Jose, J., Kollenchira, M., \& Mehta, G. (2020). Employee reactiveness and inclusive leadership: time to manage emotional diversity. South Asian Journal of Business Studies. https://doi.org/10.1108/SAJBS02-2020-0042

Ryan, J. (2006). In clusive Leader sh ip an $d$ Social Justice for Sch ools. 3-17.

Silva, A. (2016). What is Leadership ? Video: What is leadership? Journal of Business Studies Quarterly, $8(1), \quad 1-5 . \quad$ Retrieved from https://search.proquest.com/openview/da932f3ddd4 96ce36e7f30f9e133b141/1?pqorigsite $=$ gscholar $\&$ cbl $=1056382$

Saunders, Sabrina E. R., 2005. Native Leaders - Leading Natives: Looking At Inclusionary Tactics For First Nations Implementations. A Final Research Paper submitted for 1042: Educational Leadership \& Cultural Diversity Dr. Jim Ryan Theory \& Policy Studies Ontario Institute for Studies in Education of the University of Toronto.

Thompson, H., \& Matkin, G. (2019). The Evolution of Inclusive Leadership Studies: A literature review. Journal of Leadership Education, 19(3). https://doi.org/10.12806/v19/i3/r2

Wuffli, Peter A., 2016. Inclusive Leadership: A Framework for the Global Era. Springer.

Ye, Q., Wang, D., \& Li, X. (2019). Inclusive leadership and employees' learning from errors: A moderated mediation model. Australian Journal of Management, $\quad 44(3), \quad 462-481$. https://doi.org/10.1177/0312896218805796 